\title{
Microstructural Characterization and Mechanical Behavior of a Low-Carbon 17\%Mn Steel
}

\author{
Mirelle Oliveira Spindola ${ }^{a}$, Sara Silva Ferreira de Dafé $e^{a *}$, \\ Denilson José do Carmo ${ }^{\mathrm{b}}$, Dagoberto Brandão Santos ${ }^{\mathrm{a}}$
}

\author{
${ }^{a}$ Department of Metallurgical and Materials Engineering, Universidade Federal de Minas \\ Gerais - UFMG, Escola de Engenharia - Bloco 2, Av. Antônio Carlos, 6627, Pampulha, \\ CEP 31270-901, Belo Horizonte, MG, Brazil \\ ${ }^{\mathrm{b} S}$ Serviço Nacional de Aprendizagem Industrial - SENAI, Centro Tecnológico de Fundição Marcelino \\ Corradi-CETEF, R. Lilia Antunes, 99, CEP 35680-270, Itaúna, MG, Brazil
}

Received: August 22, 2013; Revised: April 7, 2014

\begin{abstract}
Steels containing high levels of $\mathrm{Mn}, \mathrm{Si}$ and $\mathrm{Al}$ exhibit high plasticity when deformed, owing to twinning-induced plastitity (TWIP) and transformation-induced plasticity (TRIP) effects. In this study, we investigated the microstructural evolution of samples of samples of a $17 \% \mathrm{Mn}$ steel subjected to war rolling at $700^{\circ}$ and $800^{\circ} \mathrm{C}$. We also studied the effects of the microstructure of the steel samples on their mechanical behavior. Using a mathematic model the stacking fault energy of the steel was estimated to be $14.5 \mathrm{~mJ} / \mathrm{m}^{2}$. This value was indicative of a martensitic transformation. The presence of martensite and twinned austenite was verified using optical microscopy, scanning electron microscopy (SEM) and electron backscatter diffraction (EBSD) analyses. The presence of austenite and $\varepsilon$ - and $\alpha$ '-martensites was confirmed using X-ray diffraction (XRD) analyses and dilatometry. Increasing the rate of cold reduction resulted in the formation of a $\alpha^{\prime}$-martensite phase and a decrease in the volume fraction of the $\varepsilon$-martensite phase. The volume fractions of the various phases were measured by integrating the areas under the XRD peaks. The sample subjected to a cold-rolling reduction of $81 \%$ and a subsequent annealing treatment did not contain a $\alpha^{\prime}$-martensite phase, indicating that it was fully recrystallized. The Vickers microhardness of the samples increased with an increase in the cold-rolling reduction rate. However, the microhardness values of the cold-rolled samples decreased after the annealing treatment.
\end{abstract}

Keywords: manganese, warm rolling, cold rolling, recrystallization, EBSD analysis

\section{Introduction}

Steels containing $\mathrm{Mn}, \mathrm{Si}$ and $\mathrm{Al}$ in high concentrations exhibit high mechanical strength and plasticity when deformed, owing to mechanical twinning or because of a martensitic transformation. The former is known as twinning induced plasticity (TWIP), while the latter is called transformation induced plasticity (TRIP) ${ }^{1}$.

An important parameter determining the type of deformation mechanism in steels is their stacking fault energy (SFE). According to Dumay et al. ${ }^{2}$, for SFE values greater than $18 \mathrm{~mJ} / \mathrm{m}^{2}$, the TWIP effect tends to occur, while for lower values, the TRIP effect is predominant, with an $\alpha$ '-martensite phase being formed for SFE smaller than $12 \mathrm{~mJ} / \mathrm{m}^{2}$. This, however, results in a decrease in the ductility of the steel $^{3}$. Furthermore, the SFE is dependent on the chemical composition and temperature of the steel. It is known that the SFE of Fe-Mn-C alloys is relatively low. Further, in alloys with a Mn content (wt \%) of less than $15 \%$, TRIP effect dominates, while for a Mn content higher than $25 \%$ the TWIP effect is dominant. On the other hand, in alloys with a Mn content between $15 \%$ and $25 \%$, the TRIP and TWIP effects can coexist ${ }^{4}$.

*e-mail: saradafe@gmail.com
Thus, understanding the deformation mechanism in these alloys when they are subjected to external loads is extremely important, because the mechanism determines the mechanical properties of the alloys, that make them suited for industrial applications such as their mechanical strength, ductility and formability.

In this study, we investigated the evolution of the microstructure of a $17 \% \mathrm{Mn}$ steel after it had been subjected to warm and cold rolling with different reductions and subsequent annealing treatments. We also evaluated the effects of the microstructure of the steel on its mechanical behavior. The treatments to which the steel was subjected were meant to produce an ultrafine-grained steel that exhibited TRIP effect.

\section{Material and Methods}

Samples of the steel, whose chemical composition (wt \%) is shown in Table 1, were homogenized at $1100^{\circ} \mathrm{C}$ for $2 \mathrm{~h}$. Next, the samples were reheated to $700^{\circ} \mathrm{C}$ for $30 \mathrm{~min}$ and then warm rolled till their thickness had been reduced by $56 \%$. After being warm rolled, the samples were mechanically descaled and then cold rolled to achieve thickness reductions of $4,35,50$, and $81 \%$. 
Finally, the samples were annealed at $700^{\circ} \mathrm{C}$ and $800^{\circ} \mathrm{C}$ for $30 \mathrm{~min}$, in order to produce a recrystallized microstructure. Immediately after the completion of the annealing process, the samples were quenched in water.

In order to be able to predict the deformation mechanisms of the various samples, their SFE values were estimated using the model proposed by Dumay et al. ${ }^{2}$. The evolution in the microstructure of the samples was observed after each cold-reduction and annealing step. The microstructure was analyzed using optical and scanning electron microscopy (SEM) (Inspect S50, FEI). The samples were ground and then polished electrolytically in a solution containing $37 \mathrm{~mL}$ $\mathrm{H}_{3} \mathrm{PO}_{4}, 153 \mathrm{~mL} \mathrm{CH} \mathrm{COOH}_{3}$ and $10 \mathrm{~mL} \mathrm{H}_{2} \mathrm{O}$. Next, they were etched, first with Nital $(10 \%)$ and then with Klemm's I reagent ${ }^{5}$. Electron backscatter diffraction (EBSD) analyses were also performed to study the microstructure, using an EDAX system with a Digi View camera and the software OIM 6.1. For these analyses the samples were first polished mechanically with diamond paste $(0.25 \mu \mathrm{m})$ and then with colloidal silica $(0.05 \mu \mathrm{m})$.

Dilatometry tests were performed to determine whether the reverse transformation of martensite into austenite occurred in the sample. The tests were performed at temperatures ranging from room temperature to $1000^{\circ} \mathrm{C}$; the heating rate was $1^{\circ} \mathrm{C} / \mathrm{s}$. The samples were subsequently cooled in air. The phase-transformation temperatures were determined from the obtained dilatometry curves and their derivatives as functions of the temperature.

$\mathrm{X}$-ray diffraction (XRD) analyses were performed using a PANalytical Empyrean diffractometer with a Nimonochromator and a copper tube that emitted $\mathrm{Cu} \mathrm{K} \alpha$ radiation $(\lambda=0.1540 \mathrm{~nm})$. The scans (room temperature, $45 \mathrm{~mA}$ and $40 \mathrm{kV}$ ) were performed in the continuous mode for values $2 \theta$ ranging from $10^{\circ}$ to $110^{\circ}$. The interval between each acquisition was $0.02^{\circ}$, and the step time was $1 \mathrm{~s}$. The

Table 1. Chemical composition of the investigated steel (wt $\%$ ).

\begin{tabular}{cccccc}
\hline Element & Mn & Al & Si & Ni & C \\
\hline Content & 17.0 & 3.0 & 2.0 & 1.0 & 0.08 \\
\hline
\end{tabular}

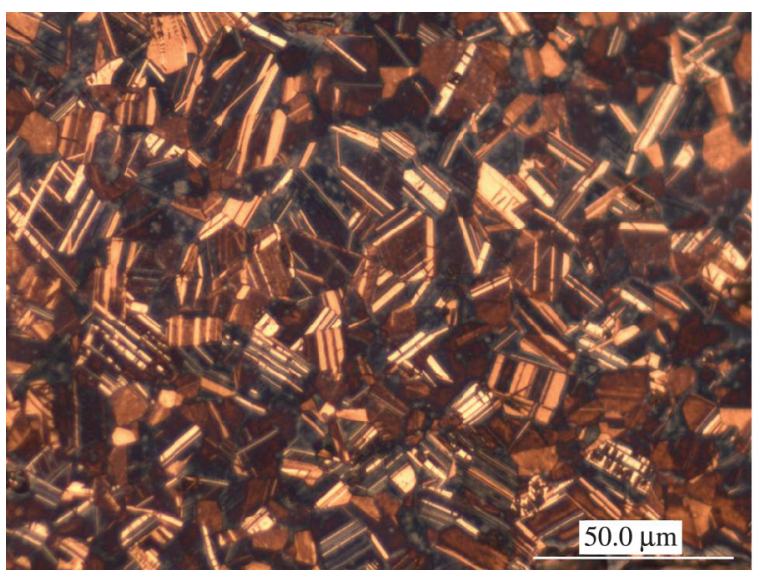

(a)
XRD analyses were performed in order to identify the phases of the samples and to determine their relative amount using the integral breadth method ${ }^{5}$. This method takes in account the highest intensity peaks corresponding to the austenite phase (i.e., the (111), (200), (220), and (311) planes), the $\alpha^{\prime}$ martensite phase (i.e., the (110), (200), (211), and (220) planes) and the $\varepsilon$ martensite (i.e., the (100), (002), (101), and (102) planes). The calculations were performed using the peak-fitting tool of the software Origin ${ }^{\mathrm{TM}}$.

The mechanical behaviors of the samples were evaluated on the basis of their Vickers microhardness values, which were determined using a load of $2.91 \mathrm{~N}$ (300 g); 20 indentations were made in each sample.

\section{Results and Discussion}

Using the model proposed by Dumay et $a .^{2}$, the SFE of the steel was estimated to be $14.5 \mathrm{~mJ} / \mathrm{m}^{2}$. This indicated that a possible martensitic transformation was also responsible by the deformation, in addition to twinning. The procedure for calculating the SFE has described in detail elsewhere ${ }^{6}$. Saeed-Akbari et al. ${ }^{7}$ calculated the SFE values for steels containing $10-35 \% \mathrm{Mn}$ (wt $\%)$. The SFE reported by them for a Mn content of $15 \%$ wt $\%$ was similar to the one obtained in the present study. In addition, the SFE value calculated in this study was similar to that proposed by Lee and $\mathrm{Choi}^{8}$ for steels with a similar Mn content and an austenitic phase with a small grain size.

Figure 1 shows optical micrographs of the samples annealed at $800^{\circ} \mathrm{C}$. Austenite grains with annealing twins as well as a martensite phase were observed. In principle Klemm's I etchant reveals austenite as yellow, brown, or blue, $\alpha^{\prime}$-martensite as dark brown, and $\varepsilon$-martensite as white; however, variations in these shades can occur from sample to sample.

Figure 2 shows SEM images of the samples annealed at $800^{\circ} \mathrm{C}$ after being subjected to cold-rolling reductions of 35 and $50 \%$. The images confirm the existence of the phases as well as the microstructural heterogeneities noticed in the optical micrographs. According to Ding et al. ${ }^{4}$, the $\varepsilon$-martensite phase nucleates through the stacking faults

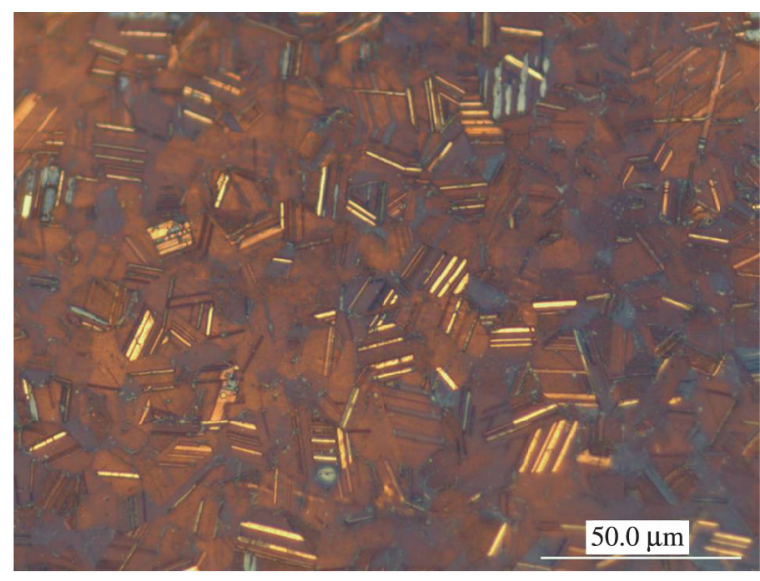

(b)

Figure 1. Optical micrographs of the samples annealed at $800^{\circ} \mathrm{C}$ after cold-rolling reductions of (a) $50 \%$ and (b) $81 \%$. 
generated by partial dislocations or owing to the overlapping of these faults, which are created at the active slip-plane intersections or at grain boundaries and twins. Moreover, according to Liang ${ }^{9}$, the crystallographic orientations of the different variants of $\varepsilon$-martensite differ by approximately $70^{\circ}$, as indicated by the red arrows in Figures $2 \mathrm{a}$ and $\mathrm{c}$. The $\alpha^{\prime}$-martensite phase is usually formed at the intersection of two $\varepsilon$-martensite laths. However, other slip planes also can act as nucleation sites for this phase $e^{3,4,9}$, as denotes by the black arrows in Figures $2 b$ and c.

Figure 3 shows inverse pole figure (IPF) and image quality (IQ) maps of the samples warm rolled (Figure 3a), cold rolled with a reduction of $35 \%$ and subsequently annealed at $800^{\circ} \mathrm{C}$ (Figure $3 \mathrm{~b}$ ), and cold rolled with a reduction of $81 \%$ and subsequently annealed at $800^{\circ} \mathrm{C}$ (Figure 3c). The black arrows indicate $\alpha$-martensite, the red ones $\varepsilon$-martensite, and the yellow ones twins. Note that, in the warm-rolled sample (Figure 3a), the austenite grains were elongated, and twins were present. In addition, there was evidence of the formation of a $\varepsilon$-martensite phase. In the case of the sample shown in Figure $3 b$ the microstructure was extremely complex and contained twinned austenitic grains and $\alpha^{\prime}$ - and $\varepsilon$-martensite phases. In this figure, the $\Sigma 3$ twin boundaries are shown as red lines, while the $\Sigma 9$ twin boundaries are shown as blue one. It was hard to identify the boundaries because the number of twins the small analyzed area was low. In addition, large amount of martensite was observed in the analyzed area. For these reasons, the frequency of twinning in the austenite phase was not estimated. Finally, the sample subjected to a cold reduction of $81 \%$ and annealing at $800^{\circ} \mathrm{C}$ exhibited ultrafine twinned austenitic grains (Figure 3c), as it was subjected to a greater degree of work-hardening after the cold-rolling process. A deformation this extensive induces numerous defects in the grains, making it difficult index the Kikuchi pattern ${ }^{10}$. In addition, the scanned area was relatively small and thus not suitably representative for analyzing the texture.

Figure 4 shows the dilatometry curves obtained by heating the samples continuously, as well as the derivatives of the curves. Figures $4 \mathrm{a}$ and $\mathrm{d}$ show that a phase transformation occurred over the temperature range of $100^{\circ} \mathrm{C}$ to $250^{\circ} \mathrm{C}$; this transformation was a reverse one, that is, from $\varepsilon$-martensite to austenite. For temperatures ranging from $500^{\circ} \mathrm{C}$ to $700^{\circ} \mathrm{C}, \alpha^{\prime}$-martensite reverse transformation was observed in the austenite phase of the samples cold rolled to reductions of $35 \%$ (Figure $4 \mathrm{~b}$ ) and $81 \%$ (Figure $4 \mathrm{c}$ ); however, the $\varepsilon$-martensite phase was barely noticeable. These observations demonstrate that the $\varepsilon$-martensite phase occurs only in steel samples subjected to low deformations and having a low SFE. On the other hand, in samples subjected to higher deformations, $\alpha^{\prime}$-martensite phase is more likely to form. These observations were keeping with the results reported in the literature ${ }^{4}$.

The inflections in the dilatometric curves of the cold-rolled samples (Figures $4 \mathrm{~b}$ and c) for temperatures ranging from $750^{\circ} \mathrm{C}$ to $850^{\circ} \mathrm{C}$ corresponded to a magnetic transformation, that is, a transformation of the ferromagnetic material ( $\alpha^{\prime}$-martensite) to a paramagnetic one (austenite).

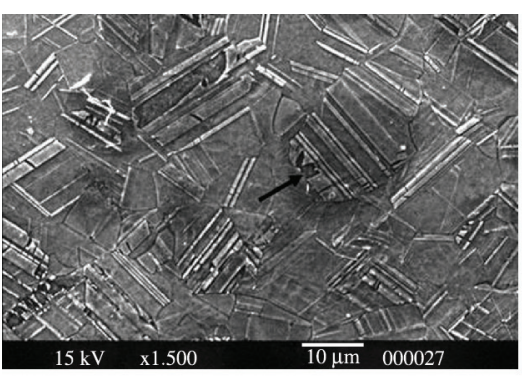

(a)

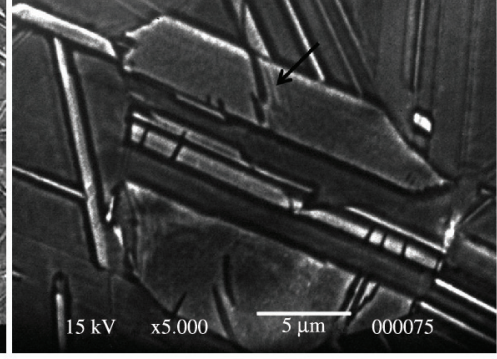

(b)

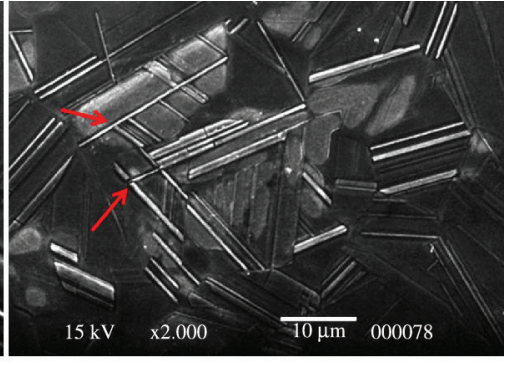

(c)

Figure 2. SEM images of the samples annealed at $800^{\circ} \mathrm{C}$ after cold-rolling reductions of (a and b) $35 \%$ and (c) $50 \%$.

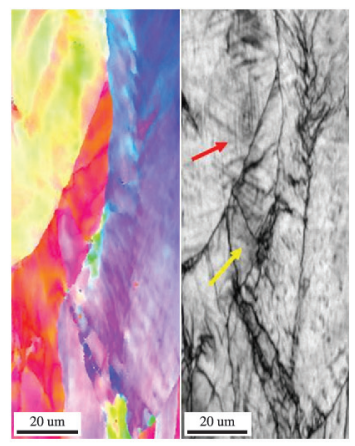

(a)

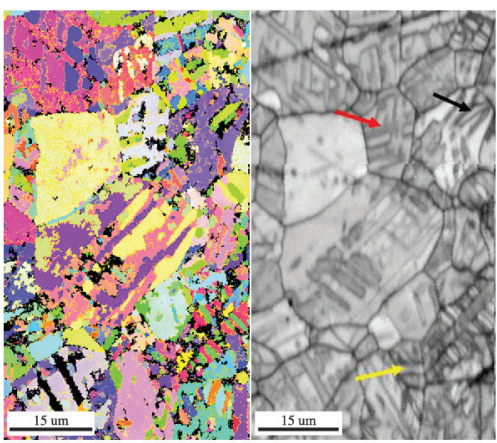

(b)

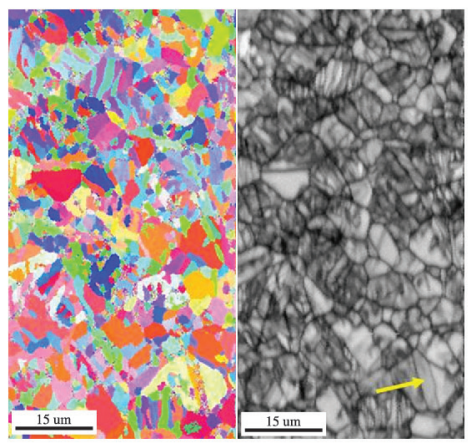

(c)

Figure 3. IPF and IQ maps of the samples (a) warm rolled, (b) cold rolled with a reduction of $35 \%$ and annealed at $800{ }^{\circ} \mathrm{C}$, and (c) cold rolled with a reduction of $81 \%$ and annealed at $800^{\circ} \mathrm{C}$. 


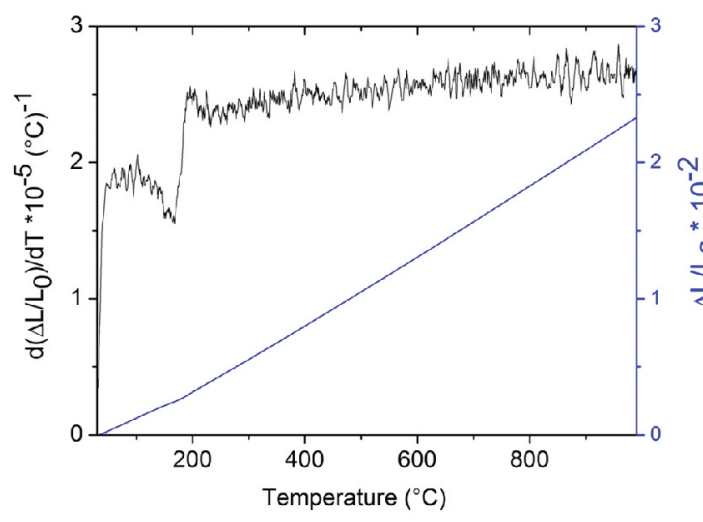

(a)

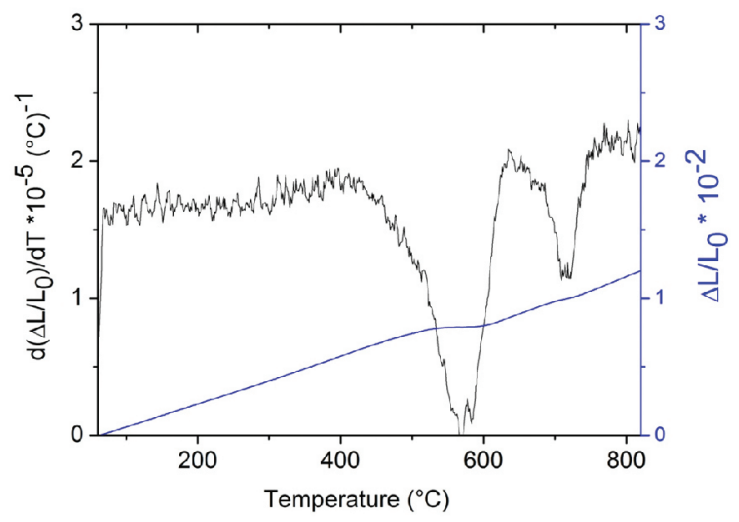

(c)

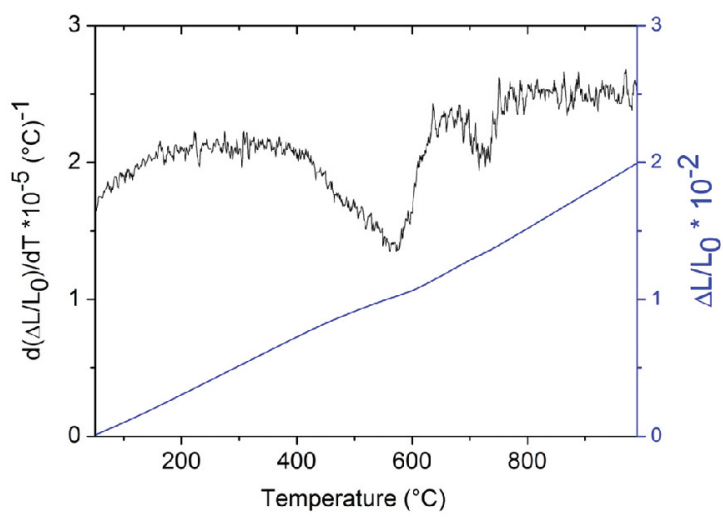

(b)

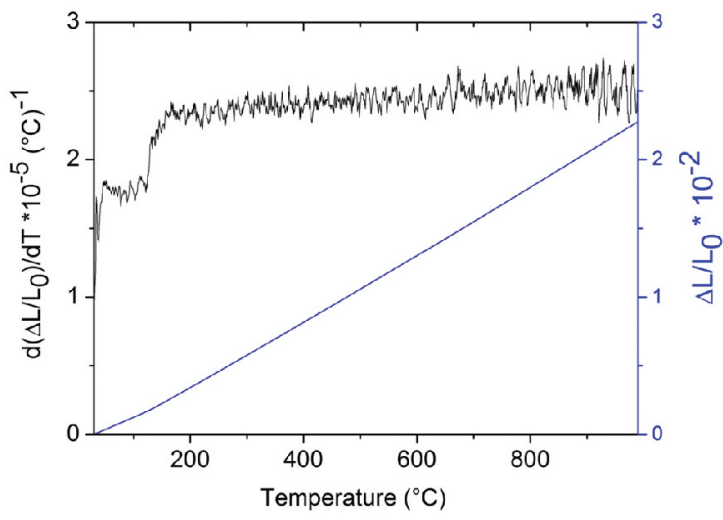

(d)

Figure 4. Dilatometric curves, as well as their derivatives, of the samples (a) warm rolled, (b) cold rolled with a reduction of 35\%, (c) cold rolled with a reduction of $81 \%$, and (d) cold rolled with a reduction of $81 \%$ and annealed at $800^{\circ} \mathrm{C}$ for 300 min.

For pure iron, the Curie temperature is $770^{\circ} \mathrm{C}^{[11]}$. Lu et al. ${ }^{3}$ reported that for a steel containing $17 \% \mathrm{Mn}$, the volume fractions of the $\alpha$-martensite and $\varepsilon$-martensite phases increased and decreased, respectively, in case of high tensile deformations. However, for an alloy containing $22 \%$ $\mathrm{Mn}$, they reported that, at high deformations, there was an increase in the volume fractions of both martensites. The chemical composition of the steel investigated in the present study was similar to the first composition mentioned above ${ }^{3}$. Hence, the observation (Figure 5) that the sample subjected to a cold-rolling reduction of $81 \%$ contained a greater amount of $\alpha$-martensite than did the sample cold roduced by $35 \%$ was in agreement with the previously reported studies ${ }^{3}$.

The results of the XRD analyses of the samples annealed at $800^{\circ} \mathrm{C}$ suggested the presence of austenite as well as, $\varepsilon$ - and $\alpha^{\prime}$-martensite phases (Figure 6). Figure 7 shows the volume fractions of the different phases corresponding to the samples subjected to the different cold-rolling reductions and subsequent annealing at $800^{\circ} \mathrm{C}$. It can be seen that, for reductions of up to $50 \%$, the volume fraction of each phase remained practically constant. On the other hand, in the case of the sample subjected to a cold-rolling reduction of $81 \%$, the relative amount of the austenite phase increased; this was accompanied by a decrease in the volume fraction of the $\varepsilon$-martensite and the complete disappearance of the

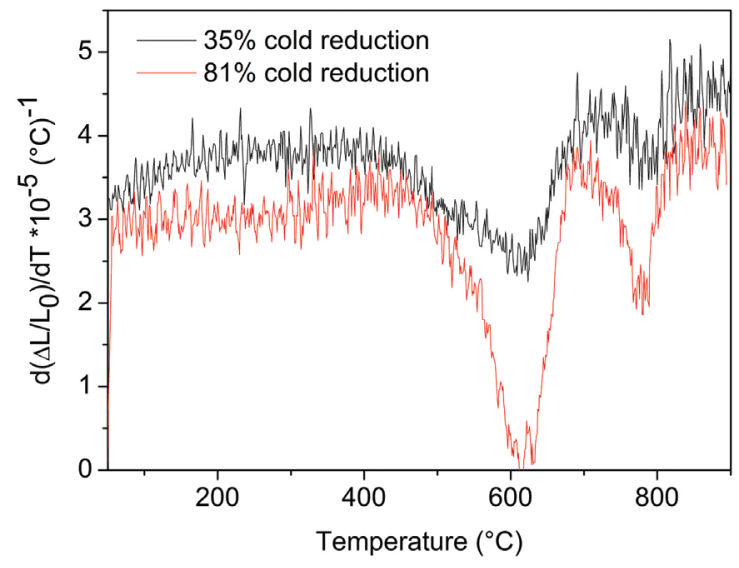

Figure 5. Comparison of the derivatives of dilatometric curves as functions of the relative dilatation of the samples subjected to cold-rolling reductions of $35 \%$ and $81 \%$.

$\alpha^{\prime}$-martensite phase. These results indicated that subjecting the samples to a reduction of $81 \%$ by cold rolling and subsequently annealing them at $800^{\circ} \mathrm{C}$ resulted in a greater degree of recrystallization.

The dilatometric curve (Figure 4d), optical micrograph (Figure 1b), EBSD analysis results (Figure 3c) of the 
sample annealed at $800^{\circ} \mathrm{C}$ after a $81 \%$ cold-rolling reduction corroborated the results of the XRD analysis of the sample (Figure 6), namely, that subjecting the sample to these treatments resulted in the complete removal of the $\alpha$ '-martensite phase.

Tavares et al. ${ }^{12}$ analyzed a $17 \mathrm{Mn}-2 \mathrm{Al}$ steel and found that samples of the steel cold rolled with reductions of 27.5 to $94.8 \%$ and subsequently annealed at $800^{\circ} \mathrm{C}$ exhibited a fully austenitic structure. However, these results ${ }^{12}$ were not in agreement with those obtained in the present study, probably because of the differences in the different chemical

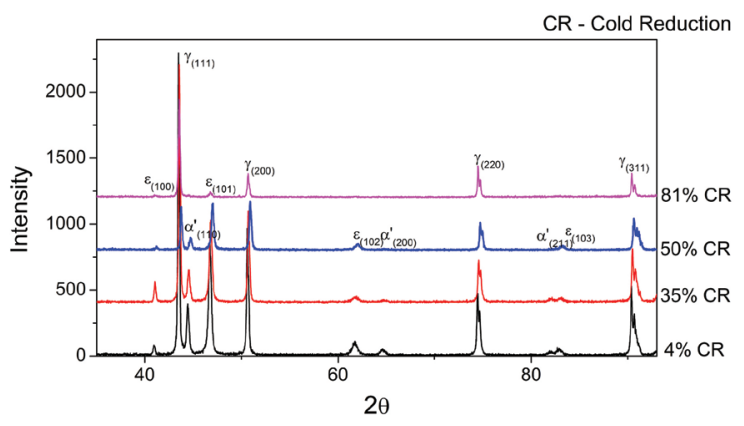

Figure 6. XRD patterns of the samples subjected to different cold reductions and annealed at $800^{\circ} \mathrm{C}$ for $30 \mathrm{~min}$.

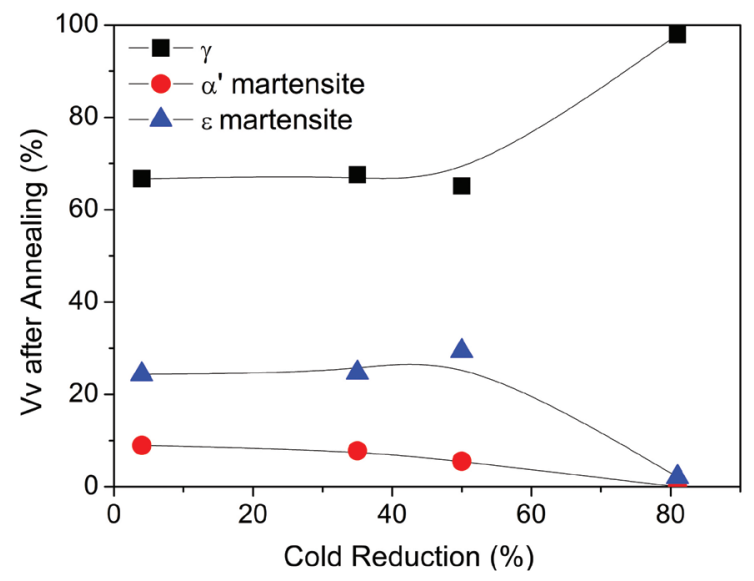

Figure 7. Phase volume fractions $\left(\mathrm{V}_{v}\right)$ of the samples subjected to the different cold reductions and annealed at $800^{\circ} \mathrm{C}$. compositions of the two steels. In addition to containing Mn and Al, the steel investigated in the present study also had a considerably high Si content. A high Si content enhances the possibility of martensite formation, because Si reduces the $\mathrm{SFE}^{[2]}$ of the steel. Another factor that could have had an effect on the final microstructure was the duration of the annealing treatment. The annealing period used by Tavares et al. ${ }^{12}$ was twice as long as that used in the present study.

Thus, it was confirmed through metallographic analyses, dilatometry and XRD analyses that, in steels with high Mn content, $\alpha^{\prime}$-martensite phase is formed from the $\varepsilon$-martensite phase at high deformations.

Few studies have reported finding the three phases $\left(\gamma, \alpha^{\prime}\right.$ and $\left.\varepsilon\right)$ using the techniques employed in this study, especially dilatometry. Ding et al. ${ }^{4}$ studied the mechanical behavior under tensile stress of a TRIP/TWIP steel containing $18.8 \% \mathrm{Mn}$ and found that a $\gamma \rightarrow \varepsilon \rightarrow \alpha^{\prime}$ transformation occurs as the strain is increased. This finding corroborates the results obtained in the present study.

Figure 8 shows the variation in the Vickers microhardness values of the samples subjected to the different deformation conditions and annealed at different temperatures. As expected, it was found that the microhardness increased as the degree of cold-rolling reduction was increased. This was due to an increase in the number of heterogeneities in the microstructure, such as dislocations and mechanical twins, in addition to the martensitic transformation. As expected, after the recrystallization of the samples, the Vickers microhardness decreased with an increase in the degree of cold-rolling reduction. In the case of the samples annealed at $700^{\circ} \mathrm{C}$ the microhardness increased continuously with an increase in the degree of cold-rolling reduction. On the other hand, for the samples annealed at $800^{\circ} \mathrm{C}$, the microhardness increased for reductions ranging from $4 \%$ to $35 \%$. For reductions greater than $35 \%$, the microhardness remained almost constant (within the standard deviation range).

Even though the sample cold rolled with $81 \%$ a reduction of $81 \%$ was subjected to a greater deformation and exhibited a higher recrystallized-phase-volume fraction, the Vickers microhardness of this sample was comparable to those of the samples with the incompletely recrystallized microstructures, which contained $\varepsilon$ - and $\alpha^{\prime}$-martensite phases. This was owing to the residual strain hardening of the former sample and because it had a more refined microstructure (see Figure 3).

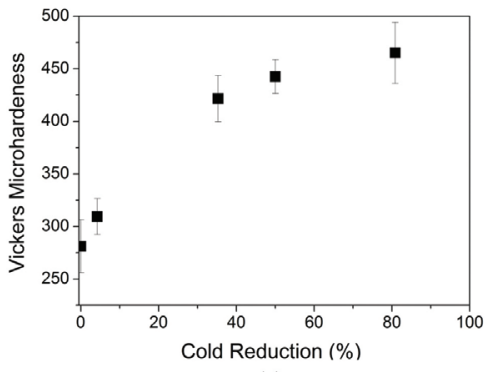

(a)

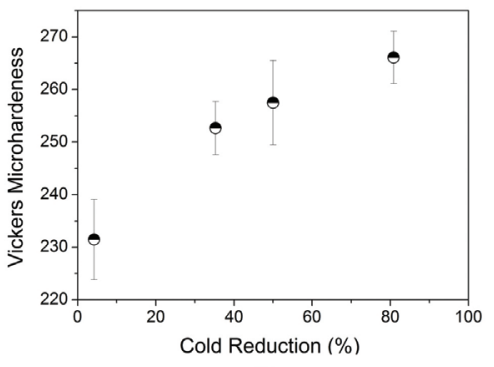

(b)

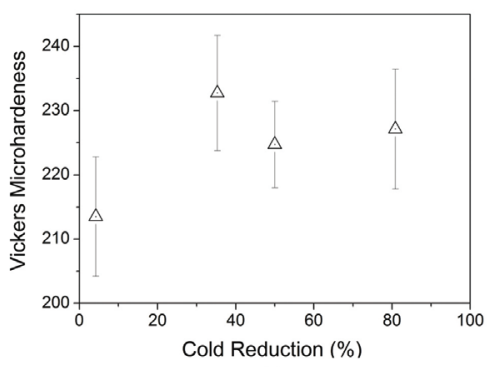

(c)

Figure 8. Vickers microhardness values of the samples (a) subjected to different cold reductions and annealed at (b) $700^{\circ} \mathrm{C}$ and (c) $800^{\circ} \mathrm{C}$ for $30 \mathrm{~min}$. 


\section{Conclusions}

The primary results of the study were the following:

- The stacking fault energy of the investigated steel was estimated to be $14.5 \mathrm{~mJ} / \mathrm{m}^{2}$. This value suggested that a possible martensitic transformation was the deformation mechanism, in addition to dislocation gliding and twinning.

- The cold-rolled samples contained austenite and $\alpha$ martensite; however, the presence of $\varepsilon$-martensite in the samples subjected to higher deformations could not be detected using dilatometry.

- After cold-rolling, the volume fraction of the $\alpha$ martensite phase was higher in the sample subjected to the $81 \%$ reduction that in the sample subjected to the $35 \%$ reduction.

- The microstructures of the samples annealed at $700^{\circ} \mathrm{C}$ and $800^{\circ} \mathrm{C}$ exhibited austenite and $\varepsilon$ - and $\alpha^{\prime}$ martensites. The exception was the sample cold rolled to a reduction of $81 \%$ and annealed at $800^{\circ} \mathrm{C}$. This

\section{References}

1. Frommeyer G, Brüx U and Neumann P. Supra-ductile and high-strength manganese-TRIP/TWIP steels for high energy absorption purposes. ISIJ International. 2003; 43(3):438-446. http://dx.doi.org/10.2355/isijinternational.43.438

2. Dumay A, Chateau JP, Allain S, Migot S and Bouaziz O. Influence of addition elements on the stacking-fault energy and mechanical properties of an austenitic Fe-Mn-C steel Materials Science and Engineering A. 2008; 483-484:184-187. http:// dx.doi.org/10.1016/j.msea.2006.12.170

3. Lu F, Yang P, Meng L, Cui F and Ding H. Influences of thermal martensites and grain orientations on strain-induced martensites in high manganese TRIP/TWIP Steels. Journal of Materials Science \& Technology. 2011; 27(3):257-265, 2011.

4. Ding H, Ding H, Song D, Tang Z and Yang P. Strain hardening behavior of a TRIP/TWIP steel with $18.8 \%$ Mn. Materials Science and Engineering A. 2011; 528(3):868-873. http:// dx.doi.org/10.1016/j.msea.2010.10.040

5. Sugimoto K, Usui N, Kobayashi M and Hashimoto S. Effects of volume fraction and stability of retained austenite on ductility of TRIP-aided dual-phase steels. ISIJ International. 1992; 32:1311-1318. http://dx.doi.org/10.2355/ isijinternational.32.1311

6. Dafé S, Sicupira F, Matos F, Cruz N, Moreira D and Santos D. Effect of cooling rate on $\left(\varepsilon, \alpha^{\prime}\right)$ martensite formation in indicated that the recrystallized fraction was higher in the samples annealed at this temperature.

- The Vickers microhardness of the samples increased with an increase in the degree of cold-rolling reduction. However, the samples cold-rolled samples subjected to the thickness reductions of 35,50 , and $81 \%$ and annealed at $800^{\circ} \mathrm{C}$ exhibited similar microhardness values. This was because the higher degrees of deformations resulted in a more refined microstructure. The samples subjected to lower degrees of deformations continued to exhibit $\varepsilon$ - and $\alpha$-martensite phases in their microstructure.

\section{Acknowledgements}

The authors acknowledge financial support from the Conselho Nacional de Desenvolvimento Científico e Tecnológico (CNPq) and to the Coordenação de Aperfeiçoamento de Pessoal de Nível Superior (CAPES). They also wish to thank the staff of SENAI/CETEF for assistance with the dilatometry analyses.

twinning/transformation-induced plasticity Fe-17Mn-0.06C steel. Materials Research. 2013; 16(6):1229-1236. http:// dx.doi.org/10.1590/S1516-14392013005000129

7. Saeed-Akbari A, Imlau J, Prahl U and Bleck W. Derivation and variation in composition-dependent stacking fault energy maps based on subregular solution model in highmanganese steels. Metallurgical and Materials Transactions A. 2009; 40(13):3076-3090. http://dx.doi.org/10.1007/s11661009-0050-8

8. Lee YK and Choi CS. Driving force for $\gamma \rightarrow \varepsilon$ martensitic transformation and stacking fault energy of $\mathrm{g}$ in $\mathrm{Fe}-\mathrm{Mn}$ binary system. Metallurgical and Materials Transactions A. 2000; 31(2):355-360, 2000.

9. Liang X. Structure and mechanical properties of Fe-Mn alloys. Beijing: University of Science and Technology; 2008. p. 254.

10. Verbeken K, Caenegem NV and Raabe D. Identification of $\varepsilon$ martensite in a Fe-based shape memory alloy by means of EBSD. Micron. 2009; 40(1):151-156. PMid:18280172. http:// dx.doi.org/10.1016/j.micron.2007.12.012

11. Cullity $\mathrm{BD}$ and Graham $\mathrm{CD}$. Introduction to magnetic materials. 2th ed. USA: Willey; 2009. PMid:19757932.

12. Tavares SSM, Lafuente A, Miraglia S and Fruchart D. X-ray diffraction and magnetic analysis of deformation induced martensites in a Fe-17Mn-1.9Al-0.1C steel. Journal of Materials Science \& Technology. 2002; 37(8):1645-1648. http://dx.doi.org/10.1023/A:1014948831730 